\title{
Digital Informasi Kehadiran Status Dosen ITB STIKOM Bali Berbasis Web
}

\author{
Pande Putu Gede Putra Pertama \\ Institut Teknologi dan Bisnis STIKOM Bali; Jalan Raya Puputan No 86 Renon - Denpasar, (0361) 244445 \\ Jurusan Sistem Informasi, Fakultas Informatika dan Komputer, ITB STIKOM Bali \\ e-mail: putrapertama@stikom-bali.ac.id
}

\begin{abstract}
Abstrak - Salah satu fungsi pemanfaatan teknologi sebagai media yang membantu pengguna mempermudah mendapatkan informasi. Dengan penggunaan pemanfaatan teknologi digital infomasi, dapat membantu memberikan informasi status dosen di kampus. Informasi yang diperoleh berupa lokasi dan kegiatan dosen yang dilakukan di luar kampus, dimana sebelumnya informasi tersebut didapatkan secara lisan. Kebutuhan media informasi dinamis sangat diperlukan untuk memperoleh informasi yang cepat oleh mahasiswa dan dosen, mengingat tingkat intensitas kerja dosen tinggi. Metode sistem informasi ini dapat dikembangkan melalui Rapid Aplication Development dimana metode ini dianggap relatif lebih sesuai dalam rencana pengembangan aplikasi dengan ruang lingkup tidak terlalu besar. Hasil penelitian ini menggunakan web, dimana informasi yang didapatkan berupa keberadaan dosen yang akan dicari. Mahasiswa lebih mudah mendapatkan informasi dosen yang akan di cari dengan mengakses web tersebut dan melihat tampilan display web. Disamping itu, setiap dosen dapat sekaligus mengganti status kehadirannya yang ditampilkan dalam bentuk aplikasi database pada server melalui internet yang menampilkan informasi status dosen, meskipun sedang berada diluar kampus.
\end{abstract}

Kata kunci-Status Dosen, STIKOM Bali, RAD, Ajax

\section{Pendahuluan}

Dalam suatu instansi maupun perkantoran, absensi kehadiran merupakan komponen wajib yang harus dimiliki. Absensi kehadiran tersebut dapat dilakukan dengan berbagai cara. Pada instansi pendidikan, absensi kehadiran dosen maupun mahasiswa merupakan satu hal wajib saat sebelum dan setelah dilakukan proses pembelajaran dikelas maupun diluar kelas. Absensi dapat menjadi parameter perkuliahan berjalan dengan tertib dan tepat waktu. Absensi dosen menjadi tolok ukur sejauh mana kehadiran dosen dalam menyampaikan materi kepada mahasiswa [1][2]. Absensi merupakan suatu hal yang harus adapun sistem pemantauan kehadiran menggunakan sidik jari akan membuat para pemimpin dengan mudah memantau kehadiran dosen dan membuat keputusan [3][4]. Informasi merupakan hal yang penting, kecepatan penyampaian informasi dan akses data juga tidak kalah pentingnya bagi suatu organisasi untuk dapat memenangkan persaingan [5]. Informasi status dosen diperlukan dalam keadaan tertentu, seperti saat dosen tidak hadir dikelas untuk mengajar, mahasiswa dapat memperoleh informasi keberadaan dosen apakah dosen tersebut berada diruangan atau tidak serta informasi kapan dosen tersebut akan kembali keruangannya[6][7]. Sehingga hal tersebut dapat mengurangi kebingungan mahasiswa yang sedang membutuhkan dosen. Berdasarkan fenomena tersebut, maka penulis tertarik untuk merancang sebuah aplikasi media yang berhubungan dengan informasi status dosen. Media tersebut diharapkan dapat mempermudah mahasiswa dalam mengetahui keberadaan dosen yang dibutuhkan.
Perkembangan teknologi internet semakin pesat berkembang, hampir seluruh orientasi aktivitas kegiatan didasarkan pada internet. Aplikasi-aplikasi yang muncul mulai banyak dikembangkan dan sebagian besar berbasis web [8]. Untuk menunjang pengembangan aplikasi tersebut, salah satunya dengan mengganti komputer yang menggunakan desktop konvensional/biasa dengan komputer single board atau single board computer (SBC), Raspberry Pi. Adapun tujuan dalam penelitian ini adalah untuk membangun dan merancang suatu sistem otomatis presentasi kuliah menggunakan radio frequency identification (RFID) sebagai pembawa id yang akan diteruskan ke Raspberry Pi kemudian mengirimkan query sesuai dengan id yang dibaca ke server database [9].

Pada penelitian ini aplikasi informasi dosen menggunakan web service, dimana pemanfaatan teknologi aplikasi ini akan melakukan pemantauan terhadap keberadaan dosen. Adanya teknologi aplikasi ini, akan membantu sistem monitoring mahasiswa terhadap keberadaan dosen. Pada tampilan display web akan memunculkan status keberadaan dosen yang akan diakses langsung oleh mahasiswa. Dosen dapat memperbaharui status keberadaannya melalui status update yang secara otomatis akan ditampilkan melalui web display yang sudah terkoneksi internet. Status update adalah suatu bentuk informasi terbaru keberadaan dosen dikampus, pesan tersebut berisi tentang status dosen saat itu seperti tidak masuk kerja, cuti, sedang mengajar dan lain-lain. 


\section{LANDASAN TEORI}

Landasan teori pada penelitian ini adalah sebagai berikut :

\subsection{HTML}

Pada mulanya web merupakan sebuah ruang informasi internet, melalui penggunaan teknologi hyperteks, pemakai akan dituntun menemukan informasi melalui link yang sudah disediakan oleh dokumen web pada tampilan browser web. Hyper Text Markup Language (HTML) merupakan suatu rangkaian kode pada program yang menjadi basic representasi visual halaman web. HTML terdiri dari kumpulan beberapa informasi yang tersimpan dalam bentuk tag tertentu, tag-tag tersebut dapat digunakan untuk melakukan format informasi yang dimaksud [10].

Banyak teknologi-teknologi pemrograman web baru telah lahir dari pengembangan kode HTML. Meskipun demikian, sampai saat ini HTML tetap kokoh berdiri sebagai dasar dari bahasa web seperti PHP, ASP, JSP dan lain-lain. Secara umum mayoritas situs web di internet tetap menggunakan HTML sebagai teknologi utama mereka.

\subsection{Java Script dan CSS}

Java Script merupakan suatu kode-kode porgram kecil yang digunakan dalam membuat halaman web agar terlihat lebih dinamis. Melalui Java Script, navigasi menu akan lebih canggih serta dapat menampilkan efek grafis sederhana.

CSS merupakan Style Sheet Bertingkat. Dalam penggunaannya, aplikasi CSS membantu mempermudah pengembangan HTML melalui penyeragaman format pada beberapa elemen yang mirip dalam situs sehingga dapat membantu pemrograman Web jadi mudah. Ratarata saat ini, situs berbasis HTML mengaplikasikan CSS untuk menunjang tampilan. CSS disimpan pada file yang letaknya terpisah dengan ekstensi .css, jika ada perubahan maka setiap perubahan tersebut juga akan mempengaruhi semua dokumen yang terkait pada HTML. Sehingga, membutuhkan waktu yang minimal untuk merubah situs dengan jumlah halaman.

\subsection{JQuery}

jQuery merupakan pustaka Java Script yang cepat dan ringkas untuk menyederhanakan traversing dokumen HTML, penanganan event, animasi, dan interaksi Ajax yang membantu mempercepat pengembangan Web. jQuery merupakan library Java Script yang digunakan dalam pembuatan program Web yang banyak menggunakan Java Script untuk pemrosesan browser. jQuery dirancang oleh John Resig awal tahun 2006 dan saat ini jQuery merupakan salah satu library
Java Script yang banyak dipakai dan oleh penggunanya didukung Microsoft .

\section{MEtode}

Penelitian ini menggunakan metode Rapid Application Development (RAD), dalam pembuatan perangkat lunak berupa sistem, hal ini dikarenakan konsep sistem Rapid Application Development (RAD) yang terkonsentrasi pada penyempurnaan produk. Alur analisis penelitian dapat dilihat pada gambar 1 .

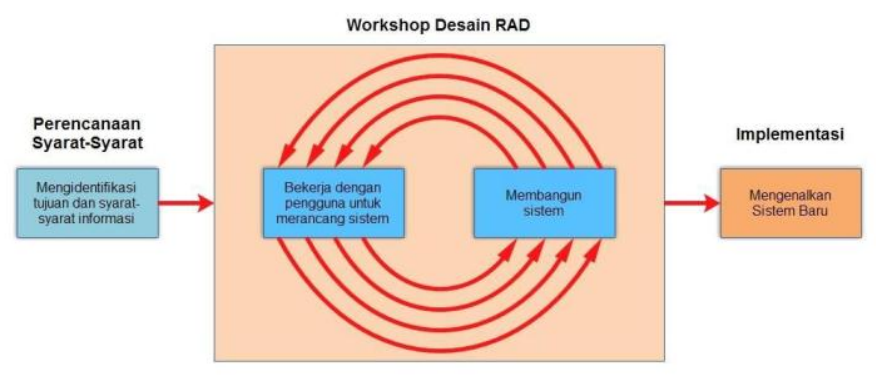

Gambar 1. Metode RAD

1. Mengidentifikasi

Pengumpulan data dilakukan melalui survei pada mahasiswa yang melakukan pencarian dosen. Selanjutnya dengan melakukan analisis terhadap masalah dan kebutuhan sistem serta jalan keluarnya. Misalnya, bagaimana cara user melakukan penambahan informasi baru serta bagaimana agar informasi yang diinginkan user dapat dengan mudah ditemukan serta tingkatan user yang diperlukan dalam menjalankan sistem

2. Perancangan Analisis dan Desain Sistem

Tahpan perancangan dapat dilakukan mulai dari analisis data terlebih dahulu yang berkaitan dengan permasalahan yang ada. Setelah analisis selesai dilanjutkan ketahapan desain dimana pada tahapan ini mendesain secara kesuluran mengenai sistem display status dosen menggunakan web.

3. Implementasi

Pada tahapan implementasi sistem yang dibagun menggunakan perangkat lunak, Java Scrip, CSS, PHP

\section{HASIL}

Adapun hasil dari aplikasi ini merupakan hasil penelitian yang dapat bentuk screen User Interface dari aplikasi yang dibangun.

\subsection{Perancangan Sistem}

Perancangan sistem yang digunakan pada aplikasi ini berbasis obyek yang merupakan tahapan yang dilakukan sebelum tahapan implementasi. Penelitian ini menggunakan Unified Modelling Language (UML). 


\subsubsection{Use Case Diagram}

Diagram Use case merupakan gambaran hasil skenario yang dilakukan untuk menterjemahkan proses yang akan dilakukan dalam sistem yang terdiri dari actor, case dan hubnungan, mulai model kebutuhan sistem sampai perancangan sistem yang akan dibangun. Berikut pada gambar 2 merupakan use case diagram dari perancangan sistem.
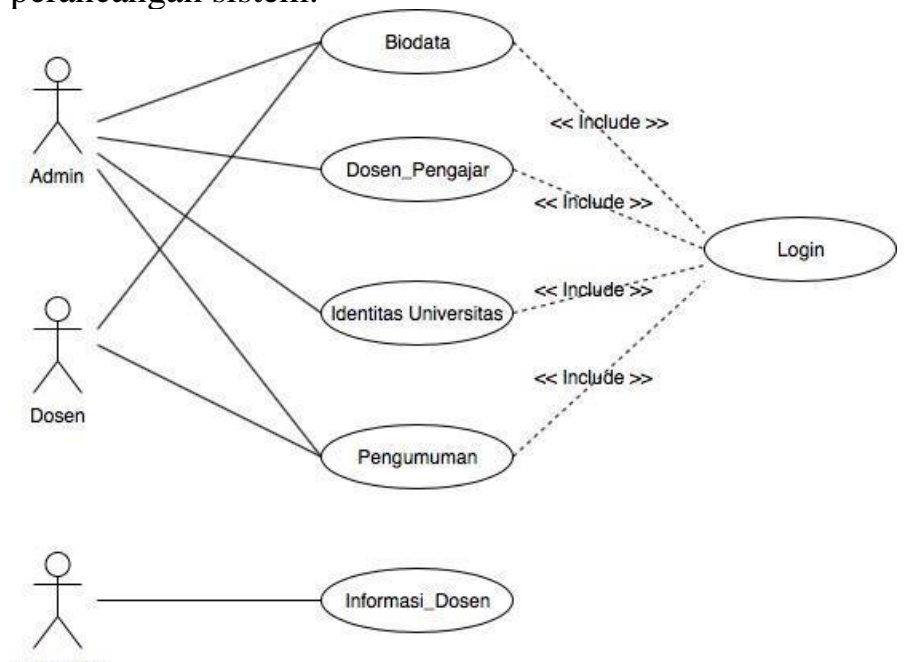

Gambar 2. Usecase Diagram Status Dosen

\subsection{Implementasi Sistem}

Implementasi sistem yang telah dibangun, mendefinisikan semua kebutuhan fungsional yang dilakukan dalam rangka persiapan perancangan system implementasi. System ini beroperasi pada web. Pada awal penggunaan system, dosen dan mahasiswa wajib melakukan login terlebih dahulu pada tampilan antar muka awal. Gambar 3 tampilan antar muka Login.
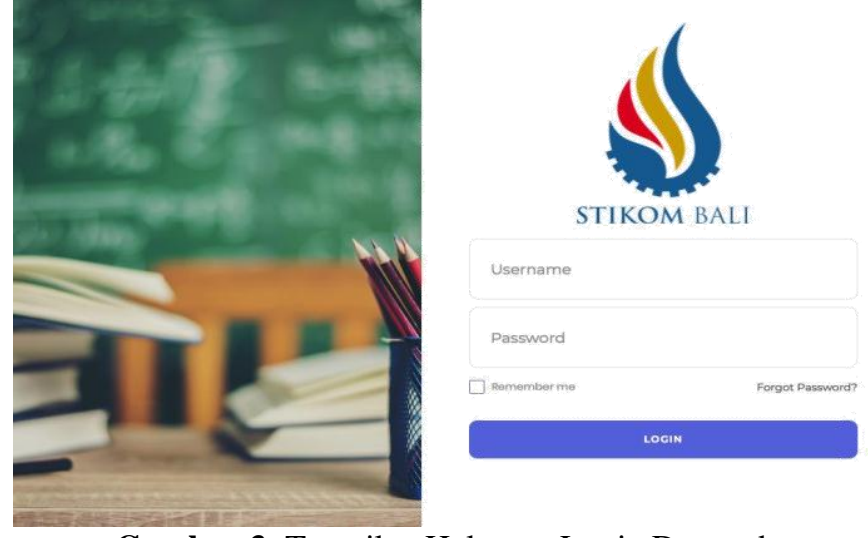

Gambar 3. Tampilan Halaman Login Dosen dan Admin

Pada gambar 4 berikut akan menunjukkan tentang tampilan menu aplikasi status admin. Menu tersebut merupakan menu utama (home) dari aplikasi status dosen. Menu tersebut dapat diakses jika dosen dan admin berhasil melakukan login.

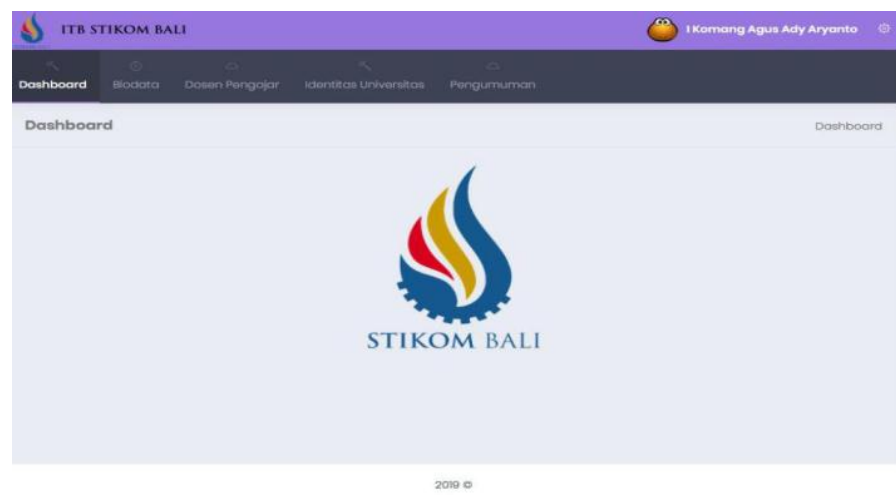

Gambar 4. Tampilan Halaman Home

Sistem ini juga terdapat tampilan pengumuman, dimana tampilan tersebut merupakan implementasi display sistem ini. Tampilan ini memproses data yang akan disampaikan ke mahasiswa. Pada gambar 5 berikut akan ditunjukkan tampilan pengumuman pada aplikasi.

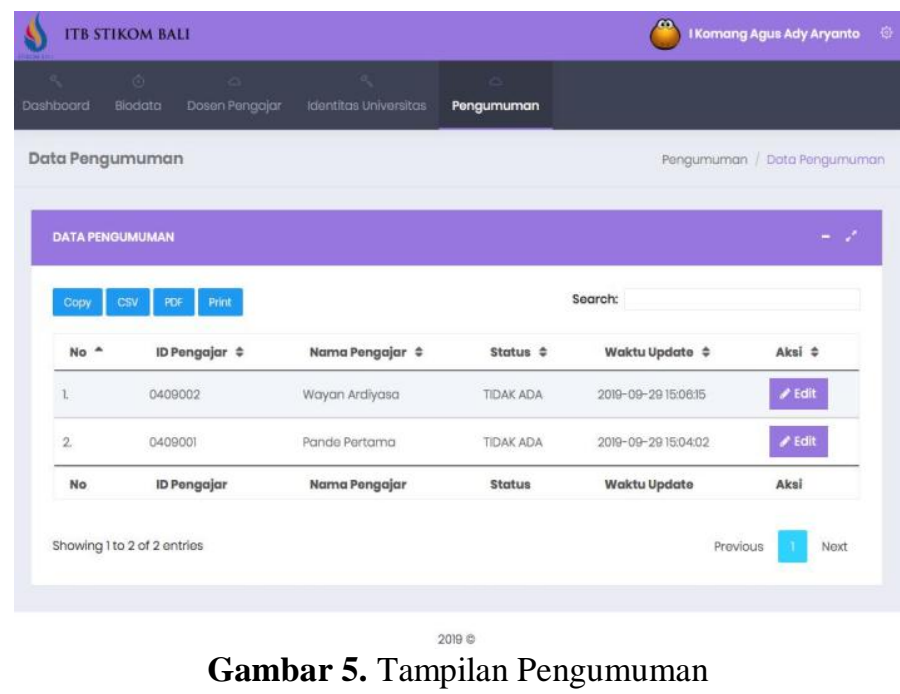

Pada gambar 6 berikut akan ditampilkan aplikasi hasil display status dosen untuk mahasiswa yang ingin mengetahui keberadaan dosen yang dibutuhkan saat itu.

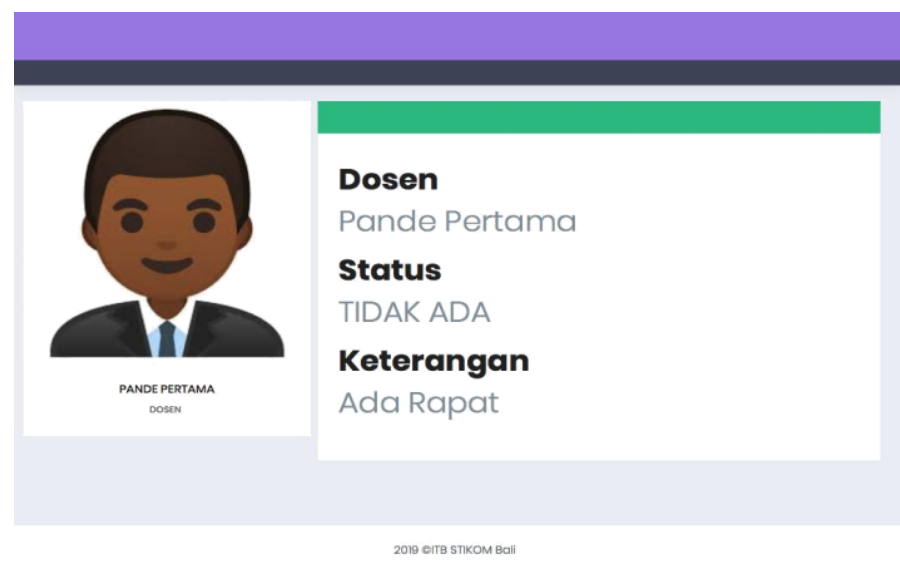

Gambar 6. Tampilan Display Status Dosen 


\section{KESIMPULAN}

Kesimpulan dalam penelitian ini adalah aplikasi display status dosen berhasil dibagun dengan menggunakan bahasa pemrograman PHP, CSS, Java Script. Dan Aplikasi ini hanya membahas mengenai status dosen saja.

\section{Daftar Pustaka}

[1] T. Fahrudin, "Pencatatan dan Pemantauan Kehadiran Perkuliahan di Lingkungan Politeknik Telkom Berbasis RFID dan Aplikasi Web," Konf. Nas. ICT-M Politek. Telkom, vol. 1, no. 1, hal. 155159, 2011.

[2] R. Pamungkas, "RANCANG BANGUN APLIKASI PENJADWALAN KULIAH PADA STKIP WIDYA YUWANA," SEMNASTEKNOMEDIA ONLINE, vol. 4, no. 1, hal. 4-11-121, Feb 2016.

[3] D. Setiawan Putra dan A. Fauzijah, "Perancangan Aplikasi Presensi Dosen Realtime Dengan Metode Rapid Application Development (RAD) Menggunakan Fingerprint Berbasis Web," $J$. Inform. J. Pengemb. IT, vol. 3, no. 2, hal. 167-171, Mei 2018.

[4] I. Ikbal dan S. Mauluddin, "Classroom Booking Information System Integrated with Course Scheduling Information System," in IOP Conference Series: Materials Science and Engineering, 2018, vol. 407, no. 1, hal. 12163.

[5] M. I. Hanafri, Triono, dan I. Luthfiudin, "Rancang Bangun Sistem Monitoring Kehadiran Dosen Berbasis Web Pada STMIK Bina Sarana Global," J. Sisfotek Glob., vol. Vol.8, no. No.1, hal. 81-86, Mar 2018.

[6] R. Firliana dan F. Rhohman, "Aplikasi Sistem Informasi Absensi Mahasiswa dan Dosen," $J$. Comput. Inf. Technol., vol. 2, no. 2, hal. 70-74, Feb 2019.

[7] M. Abdullahi, M. A. Ngadi, dan S. M. Abdulhamid, "Symbiotic Organism Search optimization based task scheduling in cloud computing environment," Futur. Gener. Comput. Syst., vol. 56, hal. 640-650, Mar 2016.

[8] M. Nurkamid, M. Dahlan, A. Susanto, dan T. Khotimah, "Pemanfaatan aplikasi jejaring sosial facebook untuk media pembelajaran," J. sains dan Teknol., vol. 3, no. 2, hal. 1-16, 2010.

[9] F. Azis dan S. Wahjuni, "Rancang Bangun Sistem Otomasi Presentasi Kuliah Menggunakan Raspberry Pi dan Radio Frequency Identification (RFID)," J. Ilmu Komput. dan Agri-Informatika, vol. 5, no. 2, hal. 76, Apr 2019.

[10] B. Sidik dan H. Pohan, Pemrograman web dengan HTML. Bandung: Informatika, 2012. 